\title{
Prediction of mode of delivery in term pregnancies: development of scoring system
}

\author{
Swathi Kotha, Pralhad Kushtagi*, Krishnapriya Radhakrishnan
}

Department of Obstetrics \& Gynaecology, Kasturba Medical College, Mangaluru, India

Received: 30 August 2015

Accepted: 09 September 2015

\author{
*Correspondence: \\ Dr. Pralhad Kushtagi, \\ E-mail: pralhadkushtagi@hotmail.com
}

Copyright: (C) the author(s), publisher and licensee Medip Academy. This is an open-access article distributed under the terms of the Creative Commons Attribution Non-Commercial License, which permits unrestricted non-commercial use, distribution, and reproduction in any medium, provided the original work is properly cited.

\begin{abstract}
Background: The objective of the study was to develop and to validate a scoring system to predict the mode of delivery.

Methods: The study involved 835 term pregnancies in labor. Backward multiple logistic regression analysis was carried out in 600 women to identify the factors independently associated with vaginal or caesarean delivery and logistic coefficients were determined to provide weightage for each of the factors. The total score was calculated for each subject. Sensitivity and specificity for vaginal/ cesarean delivery were calculated for different total scores. The validity of the scoring was studied by applying to the same data provider group retrospectively, and on other 235 laboring women prospectively recruited after the development of score.

Results: Of 600 women, $61.2 \%$ had vaginal deliveries. The significant facilitating factors for vaginal delivery were found to be maternal age of 20-25 years $(\mathrm{p}=0.02)$, multiparity $(\mathrm{p}=0.002)$, unscarred uterus $(\mathrm{p}=0.05)$, rhesus positivity $(\mathrm{p}=0.05)$, expected baby weight of $2.5-3.5 \mathrm{~kg}(\mathrm{p}=0.004)$, and with cephalic presentation, Bishop status $>4$, spontaneous onset of labor, clear liquor, and no FHR abnormality $(\mathrm{p}=0.00)$. A cut off score of 21 predicted the vaginal delivery with sensitivity, specificity, positive predictive value and negative predictive values of $80 \%, 65 \%, 70 \%$ and $76 \%$, respectively.
\end{abstract}

Conclusions: The composite score of $\leq 21$ suggests that woman will most probably have vaginal delivery and that a higher score does not always mean a caesarean delivery.

Keywords: Clinical prediction, Mode of delivery, Scoring system

\section{INTRODUCTION}

The rate of cesarean delivery is increasing in the world since the past few years. Numerous factors contribute to the rising trend of cesarean deliveries. ${ }^{1}$ An emergency cesarean delivery during labor poses increased risks for maternal morbidity and mortality and psychological trauma. $^{2}$

The concern in the minds of woman in labor and her attendants is whether she will have vaginal delivery or cesarean, more so in case of first pregnancies.
Anticipation of the problems when allowing a woman for a vaginal delivery would help to prevent unwanted outcomes and emergency cesarean deliveries. So prediction of mode of delivery as soon as the woman is in labor is a challenging task.

Many studies are available to find out the factors influencing the success of vaginal birth after cesarean delivery. ${ }^{3-12}$ It was thought to use similar philosophy in non-cesareans and nulliparas. The present study is an effort in that direction that uses non-obstetric and obstetric variables to develop a scoring system in the local population attending the facility, and to validate it. 


\section{METHODS}

Study was conducted at a District Government Hospital and the University College Hospital attached to the Medical College on west-coast in southern India, from November 2012 to June 2014 on willing participant pregnant women at term (from 36 completed weeks till 41 weeks) admitted to the labor ward. The study had approval from the Institute's Scientific and Ethics Committee.

The sample size required was calculated as 833 on the basis of incidence of cesarean delivery $(35 \%)$ in the hospital in the preceding year to obtain the results with $95 \%$ confidence interval and $85 \%$ of power. The study was conducted in two parts. First, the compilation of data from initial 600 parturients to develop a score, and later validation of the developed score in them and on the additional 235 women. Women with multiple gestation, placenta previa and previous cesarean delivery were excluded from the study.

The details of the cases recruited were recorded on the format designed for the study. Data regarding maternal age, height, body mass index (BMI), parity, history of abortions, history of infertility treatment, socioeconomic status, dietary history, comorbidities and risk factors (like hypertensive disorder complicating pregnancy, diabetes mellitus, prior myomectomy, Rhesus negativity) were collected through enquiry, from antenatal records and following physical examination.

Obstetric ultrasound ((Philips HD7 XE BOTHELL, WA USA) equipped with $3.5 \mathrm{MHz}$ curvilinear transducer) examination was carried out on admission in labor or when admitted for induction of labor, if it was not done within 2 weeks of admission, to find out amniotic fluid index (AFI), placental position, and estimated fetal weight.

\section{Development of facilitation score}

The process of developing a score followed series of steps involving identification of facilitating variable/s, their evaluation and determination of facilitation value (score) for each of the variables.

\section{Identification of facilitating variable}

Bivariate analysis using Chi - square test and Spearman's correlation coefficient of various social (socioeconomic status, diet), physical (maternal age, height and BMI), obstetric (gravidity, history of abortions, type of conception, Bishops score, fetal presentation), sonograghical (AFI, placental position, estimated fetal weight) and other risk factors (hypertensive disorder of pregnancy, diabetes, rhesus positivity, prior myomectomy) with respect to mode of delivery was carried out to identify the facilitating variable/s for vaginal delivery.

\section{Evaluation of the variable}

Backward multiple logistic regression analysis was carried out to find out the factors independently associated with vaginal or cesarean delivery. The logistic coefficient for each of the factors was obtained by taking the natural log of odds ratio.

\section{Determination of score value}

The logistic coefficient of each factor was rounded off to the nearest 0.5 or whole number to determine the score. The summation of the scores of factors was taken as the score for that subject.

\section{Determining the cut-off score}

Sensitivity and specificity for vaginal or cesarean delivery were calculated for different total scores. The score with the optimal sensitivity and specificity was taken as the cut - off. Positive and negative predictive values were calculated based on this cut off value.

\section{Validation of the determined cut-off score}

The developed score was validated in two settings by applying the derived cut-off value for total score. The calculated sensitivity, specificity, positive and negative predictive values were compared.

\section{Retrospective}

The same 600 women from whom the score was developed

\section{Prospective}

The newly recruited 235 women

For the analysis of data SPSS version 17 was used and the probability of occurrence of $5 \%$ was considered as statistically significant $(\mathrm{p}<0.05)$.

The management of labor was carried out as per the hospital protocol. The scoring for second part of the study was done by the first author (SK) and was not involved in obstetric management of cases. The assigned score was not revealed to the treating team.

\section{RESULTS}

Of the initial 600 women recruited, 367 had vaginal delivery $(61.2 \%)$. The various physical characteristics of these parturients when analysed against the mode of delivery, significant proportion of women who had vaginal delivery were aged younger than 35 years $(\mathrm{p}=0.02)$, and whether their height was more than $140 \mathrm{~cm}$ or body mass index was lesser than $25 \mathrm{~kg} / \mathrm{m}^{2}$ did not appear to be associated with higher vaginal delivery rate. 
Neither did socioeconomic status appear to influence it (Table 1). indicated that only gravidity could be a significant facilitating factor $(\mathrm{p}=0.002)$ for vaginal delivery.

The obstetric historical attributes like gravidity, prior abortion and assistance in pregnancy occurrence

Table 1: Physical characteristics - influence on the mode of delivery.

\begin{tabular}{|c|c|c|c|c|}
\hline \multirow{2}{*}{ Variables } & \multirow{2}{*}{ Cases } & \multicolumn{2}{|c|}{ Mode of delivery } & \multirow{2}{*}{ Significance } \\
\hline & & Vaginal (n, \%) & Cesarean $(\mathrm{n}, \%)$ & \\
\hline \multicolumn{5}{|l|}{ Age in years } \\
\hline$<20$ & 47 & $37(78.7)$ & $10(21.3)$ & \multirow{3}{*}{$\mathrm{p}=0.02$} \\
\hline $20-35$ & 533 & $322(60.4)$ & $211(39.6)$ & \\
\hline$>35$ & 20 & $8(40.0)$ & $12(60.0)$ & \\
\hline \multicolumn{5}{|c|}{ Height in $\mathrm{cm}$} \\
\hline$<140$ & 68 & $40(58.8)$ & $28(41.2)$ & \multirow{2}{*}{$\mathrm{p}=0.94$} \\
\hline$>140$ & 532 & $327(61.4)$ & $205(38.6)$ & \\
\hline \multicolumn{5}{|c|}{$\mathrm{BMI}$ in $\mathrm{kg} / \mathrm{M}^{2}$} \\
\hline$<18.5$ & 21 & $13(61.9)$ & $8(39.1)$ & \multirow{3}{*}{$\mathrm{p}=0.607$} \\
\hline $18.5-24.9$ & 382 & $241(63.0)$ & $141(37.0)$ & \\
\hline$>25$ & 198 & $114(57.6)$ & $84(42.4)$ & \\
\hline \multicolumn{5}{|c|}{ Socio-economic status } \\
\hline Non BPL & 77 & $52(67.5)$ & $25(32.5)$ & \multirow{2}{*}{$\mathrm{p}=0.32$} \\
\hline BPL & 523 & $315(60.2)$ & $208(39.8)$ & \\
\hline \multicolumn{5}{|l|}{ Diet } \\
\hline Mixed & 581 & $356(61.2)$ & $225(39.8)$ & \multirow{2}{*}{-0.76} \\
\hline Vegetarian & 19 & $11(57.8)$ & $8(42.2)$ & \\
\hline
\end{tabular}

BMI - Body Mass Index; BPL - Below Poverty Line Card holder; Non BPL - Without BPL card

Table 2: Obstetric characteristics - influence on mode of delivery.

\begin{tabular}{|c|c|c|c|c|}
\hline Variables & Cases & \multicolumn{2}{|c|}{ Mode of delivery } & Significance \\
\hline Gravidity & & Vaginal (n, \%) & Cesarean $(\mathrm{n}, \%)$ & \\
\hline G1 & 347 & $183(52.8)$ & $164(47.2)$ & \\
\hline G2-4 & 247 & $172(69.6)$ & $75(30.4)$ & $\mathrm{p}=0.002$ \\
\hline$\geq \mathrm{G} 5$ & 6 & $5(83.3)$ & $1(16.7)$ & \\
\hline \multicolumn{5}{|l|}{ Prior abortion } \\
\hline Absent & 522 & $320(61.3)$ & $202(38.7)$ & \multirow{2}{*}{$\mathrm{p}=0.966$} \\
\hline Present & 78 & $47(60.2)$ & $31(39.8)$ & \\
\hline $\begin{array}{l}\text { Pregnancy } \\
\text { Spontaneous }\end{array}$ & 593 & $363(61.2)$ & $230(38.8)$ & $\mathrm{p}=0.859$ \\
\hline Assisted & 7 & $4(57.1)$ & $3(42.9)$ & \\
\hline \multicolumn{5}{|l|}{ Hypertension } \\
\hline Gestational & 31 & $21(67.7)$ & $10(32.3)$ & \multirow{5}{*}{$\mathrm{p}=0.933$} \\
\hline Preeclampsia Mild & 10 & $8(80)$ & $2(20)$ & \\
\hline Severe & 6 & $3(50)$ & $3(50)$ & \\
\hline Eclampsia & 1 & 0 & 1 & \\
\hline Ch. hypertension & 1 & 0 & 1 & \\
\hline \multicolumn{5}{|l|}{ Gestational diabetes } \\
\hline on diet & 12 & $6(50)$ & $6(50)$ & \multirow{2}{*}{$\mathrm{p}=0.8$} \\
\hline on insulin & 1 & 1 & 0 & \\
\hline Prior Myomectomy & 4 & $2(50)$ & $2(50)$ & $p=0.056$ \\
\hline Rhesus blood type - Negative & 15 & $5(33.3)$ & $10(66.7)$ & $\mathrm{p}=0.057$ \\
\hline \multicolumn{5}{|l|}{ Expected fetal weight (in kg) } \\
\hline$<2.5$ & 108 & $56(51.8)$ & $52(48.2)$ & \multirow{3}{*}{$\mathrm{p}=0.19$} \\
\hline $2.5-3.5$ & 364 & $295(58.6)$ & $69(41.4)$ & \\
\hline$>3.5$ & 19 & $9(39.3)$ & $10(60.7)$ & \\
\hline
\end{tabular}

G - Gravida; Ch - Chronic 
Table 3: Sonographic and clinically determined obstetric variables and influence on mode of delivery.

\begin{tabular}{|c|c|c|c|c|}
\hline \multirow{2}{*}{ Variables } & \multirow{2}{*}{ Cases } & \multicolumn{2}{|c|}{ Mode of delivery } & \multirow{2}{*}{ Significance } \\
\hline & & Vaginal (n, \%) & Cesarean (n, \%) & \\
\hline \multicolumn{5}{|c|}{ Amniotic fluid index in $\mathrm{cm}$} \\
\hline$<5$ & 11 & $5(45.4)$ & $6(54.6)$ & \multirow{3}{*}{$\mathrm{p}=0.275$} \\
\hline $5-20$ & 479 & 293(61.1) & 186(77.4) & \\
\hline$>20$ & 21 & $9(36.8)$ & $12(63.2)$ & \\
\hline \multicolumn{5}{|l|}{ Placental position } \\
\hline Fundal & 173 & $125(72.2)$ & 48(27.8) & \multirow{5}{*}{$\mathrm{p}=0.226$} \\
\hline Upper Anterior & 238 & $146(61.3)$ & $92(38.7)$ & \\
\hline Upper Posterior & 166 & $85(51.2)$ & $81(48.8)$ & \\
\hline Lateral Right & 12 & $6(50)$ & $6(60)$ & \\
\hline Lateral Left & 11 & $5(45.5)$ & $6(54.6)$ & \\
\hline \multicolumn{5}{|l|}{ Fetal presentation } \\
\hline Cephalic & 585 & $367(62.7)$ & 218(37.3) & \multirow{2}{*}{$p=0.00$} \\
\hline Non-cephalic & 15 & $1(6.7)$ & 14(93.3) & \\
\hline \multicolumn{5}{|l|}{ Labor } \\
\hline Spontaneous & 484 & 293(60.5) & 191(39.5) & \multirow{3}{*}{$\mathrm{p}=0.00$} \\
\hline Induced - PGE2 & 105 & $53(50.4)$ & 36(49.6) & \\
\hline Induced - PGE1 & 11 & $4(36.3)$ & $7(63.7)$ & \\
\hline \multicolumn{5}{|c|}{ Duration of Rupture of Membranes in hours } \\
\hline$<12$ & 31 & $22(70.9)$ & $9(29.1)$ & \multirow{3}{*}{$\mathrm{p}=0.18$} \\
\hline $12-24$ & 15 & 7(46.6) & $8(53.4)$ & \\
\hline$>24$ & 5 & $2(40)$ & $3(60)$ & \\
\hline \multicolumn{5}{|l|}{ Bishop score } \\
\hline$<3$ & 329 & 157(47.7) & $172(52.3)$ & \multirow[t]{3}{*}{$p=0.00$} \\
\hline $4-6$ & 180 & $135(75)$ & $45(25)$ & \\
\hline$>6$ & 91 & $75(82.4)$ & 16(17.6) & \\
\hline \multicolumn{5}{|l|}{ FHR abnormality } \\
\hline Present & 76 & $23(27.4)$ & $53(72.6)$ & \multirow[t]{2}{*}{$p=0.00$} \\
\hline Absent & 524 & $344(58.1)$ & $180(41.9)$ & \\
\hline \multicolumn{5}{|c|}{ Meconium staining of amniotic fluid } \\
\hline Present & 68 & $14(20.6)$ & $54(79.4)$ & \multirow{2}{*}{$\mathrm{p}=0.00$} \\
\hline Absent & 532 & $334(62.7)$ & 198(37.3) & \\
\hline
\end{tabular}

PGE - Prostaglandin E; FHR - Fetal Heart Rate

Cephalic presentation $(\mathrm{p}=0.00)$, spontaneous onset of labor $(\mathrm{p}=0.00)$ and duration of rupture of membranes limited to 12 hours were associated with the higher vaginal delivery rate. The analysis of intrapartum variables of the participating women and mode of delivery showed that the significant proportion of women who had high Bishop Score of $>6(p=0.00)$, clear amniotic fluid $(\mathrm{p}=0.00)$ and those without any fetal heart rate abnormality $(\mathrm{p}=0.00)$ had significantly higher vaginal delivery rate. (Table 3 )

The logistic coefficient determined scores showed that expected fetal weight, Bishop Score, meconium staining of amniotic fluid, intrapartum fetal heart rate abnormality and placental locations were the significant determinants to the score. The lowest and the highest summate of scores for a parturient was 14.5 and 54.5, respectively. (Table 4).

Validation of total score vis-a-vis mode of delivery indicated that after the sum score of 20, specificity increased with increment in the score but the sensitivity gradually declined. The sum score of 21 had $80 \%$ sensitivity, $65 \%$ specificity, $70 \%$ positive prediction and $75 \%$ negative predictive value. To know the reproducibility of the validation carried out, the score cutoff was reapplied retrospectively to the population data used for developing the score $(n=600)$, and prospectively to the parturients recruited after development of the score $(n=235)$. Although the negative predictive value fell down, the other validity indicators remained respectable (Table 5). 
Table 4: Logistic coefficients and scores assigned to the variables.

\begin{tabular}{|c|c|c|c|c|c|c|c|}
\hline Variable & $\begin{array}{l}\text { Cohort } \\
\text { groups }\end{array}$ & $\begin{array}{l}\text { Logistic } \\
\text { coefficient }\end{array}$ & Score & Variable & Cohort groups & $\begin{array}{l}\text { Logistic } \\
\text { coeffici } \\
\text { ent }\end{array}$ & Score \\
\hline \multirow{3}{*}{ Age in years } & $<20$ & 1.03 & 1.5 & EFW ๑ & $<2.5$ & 1.3 & 1.5 \\
\hline & $20-35$ & 1 & 1 & & $2.5-3.5$ & 1 & 1 \\
\hline & $>35$ & 5.7 & 6 & & $>3.5$ & 5.6 & 6 \\
\hline \multirow{2}{*}{ Height in $\mathrm{cm}$} & $<140$ & 0.34 & 0.5 & EFW (S) & $<2.5$ & 1.29 & 1.5 \\
\hline & $>140$ & 1 & 1 & & $2.5-3.5$ & 1 & 1 \\
\hline \multirow{3}{*}{$\mathrm{BMI}$ in $\mathrm{kg} / \mathrm{M}^{2}$} & $<18.5$ & 3.2 & 3.5 & & $>3.5$ & 1.07 & 1.5 \\
\hline & $18.5-24.9$ & 1 & 1 & Placenta & Upper & 2.6 & 3 \\
\hline & $>25$ & 1.8 & 2 & & Fundal & 1 & 1 \\
\hline \multirow{2}{*}{$\begin{array}{l}\text { Socioeconomic } \\
\text { Status }\end{array}$} & BPL & 0.43 & 0.5 & & Lateral & 3.1 & 3.5 \\
\hline & Non BPL & 1 & 1 & AFI & $<5$ & 1.2 & 1.5 \\
\hline \multirow{3}{*}{ Gravidity } & G1 & 0.85 & 1 & & $5-20$ & 1 & 1 \\
\hline & $\mathrm{G} 2-4$ & 0.38 & 0.5 & \multirow{4}{*}{ Bishops score } & $>20$ & 0.8 & 1 \\
\hline & $\geq \mathrm{G} 5$ & 1 & 1 & & $<3$ & 5.7 & 6 \\
\hline \multirow{2}{*}{ Hypertension } & Present & 1.6 & 2 & & $4-6$ & 1.9 & 2 \\
\hline & Absent & 1 & 1 & & $>6$ & 1 & 1 \\
\hline \multirow[t]{2}{*}{ Abortions } & Present & 1 & 1 & Labor & Induced & 3.4 & 3.5 \\
\hline & Absent & 0.8 & 1 & & Spontaneous & 1 & 1 \\
\hline \multirow[t]{2}{*}{ Infertility } & Present & 3.3 & 3.5 & MSAF & Present & 8.8 & 9 \\
\hline & Absent & 1 & 1 & & Absent & 1 & 1 \\
\hline \multicolumn{2}{|l|}{ NRFHS } & 4.4 & 4.5 & NRFHS & Absent & 1 & 1 \\
\hline \multicolumn{8}{|c|}{$\begin{array}{l}\text { BMI - Body Mass Index ; AFI - Amniotic Fluid Index; MSAF - Meconium Stained Amniotic Fluid; NRFHS - Non Reassuring Feta } \\
\text { Heart Status; EFW @ - Estimated Fetal Weight clinically; EFW (S) - Estimated Fetal Weight sonologically; BPL - Below Poverty Line } \\
\text { Card holder; Non BPL - Without BPL card. }\end{array}$} \\
\hline \multicolumn{8}{|c|}{ Table 5: Determination of cut-off score and validation. } \\
\hline \multirow[t]{2}{*}{ Validation } & Score & 20 & 20.5 & 21 & 22 & 22 & \\
\hline & & $\mathrm{N}(\%)$ & $\mathrm{N}(\%)$ & $\mathrm{N}(\%)$ & $\mathrm{N}(\%)$ & & \\
\hline \multicolumn{2}{|l|}{ Vaginal Delivery } & $26(7.0)$ & $21(5.7)$ & $15(4.0)$ & $15(4.0)$ & & $1)$ \\
\hline \multicolumn{2}{|l|}{ Cesarean Delivery } & $11(4.7)$ & $15(6.4)$ & $9(3.8)$ & $16(6.8)$ & & 7.7) \\
\hline \multicolumn{2}{|l|}{ Sensitivity (\%) } & 87.5 & 84.1 & 80.6 & 72.8 & 70 & \\
\hline \multicolumn{2}{|l|}{ Specificity (\%) } & 57 & 62 & 65 & 72 & 73 & \\
\hline \multicolumn{2}{|c|}{ Positive Predictive Value } & 66.96 & 68.89 & 69.6 & 72.1 & 72 & \\
\hline \multirow{2}{*}{\multicolumn{3}{|c|}{$\begin{array}{l}\text { Negative Predictive Value } \\
\text { Validation of the Score - taking } 21 \text { as Cut Off }\end{array}$}} & 79.45 & 76.4 & 71.9 & & \\
\hline & & & & & & & \\
\hline \multicolumn{2}{|c|}{ Retrospective group } & \multicolumn{3}{|c|}{ Validation } & \multicolumn{3}{|c|}{ Prospective group } \\
\hline $\begin{array}{c}\text { Vaginal } \\
\text { delivery } \\
\mathrm{n}(\%)\end{array}$ & $\begin{array}{l}\text { Cesarean delivery } \\
\mathrm{n}(\%)\end{array}$ & \multicolumn{3}{|c|}{ Score } & $\begin{array}{l}\text { Vaginal delivery } \\
\mathrm{n}(\%)\end{array}$ & $\begin{array}{c}\text { Ces } \\
\text { deli } \\
n\end{array}$ & $\begin{array}{l}\text { rean } \\
\text { ery } \\
\text { to) }\end{array}$ \\
\hline $274(73)$ & $101(27)$ & & $<2$ & & $107(91.4)$ & 10 & 3.6) \\
\hline $93(41.3)$ & $132(58.7)$ & & $>2$ & & $43(36.4)$ & 75( & 3.6) \\
\hline & & & Sensitivi & & & .3 & \\
\hline & & & Specifici & & & .9 & \\
\hline & & Posit & ive predict & value (\%) & & .4 & \\
\hline 56 & & Nega & ive predic & value $(\%)$ & & .5 & \\
\hline
\end{tabular}




\section{DISCUSSION}

In the run up to develop a scoring system that could be of help to predict possibility of vaginal delivery in the laboring woman, most of the parturient physical characteristics, obstetric and non-obstetric particulars, labor events were looked in to. The analysis yielded insight to understand influence or otherwise of these factors in the local population on the mode of delivery.

It can be deduced from the earlier reports that in women younger than 35 years the give of pelvis is pliant and the age related medical morbidities (e.g., diabetes mellitus) are less frequent making vaginal delivery that much expectable. ${ }^{13,14}$ Age factor was one of the facilitating variables for vaginal delivery (Table 1) in the present study although the effect of confounders was not ascertained since it was outside the objective of the study.

Short statured women have high chances of cesarean delivery due to inadequacy of the pelvis. They are also women with higher rates of malpresentations, premature rupture of membranes, failed induction, in addition to labor dystocia and cephalopelvic disproportion. It is the obstetric belief and the studies have affirmed it. ${ }^{15}$ But, the present study did not find maternal height as a significant contributor to the mode of delivery which inference is in line with the guidelines. ${ }^{16}$

High BMI is a risk factor to the increased rate of cesarean delivery especially if BMI was as high as $>31 \mathrm{~kg} / \mathrm{M}^{2}{ }^{17-20}$ The high score obtained for the maternal BMI of $<18.5$ could not be explained. The present study used the more rational pre-pregnancy or first trimester parameters for calculating BMI unlike the use of admission BMI as in other studies. ${ }^{18}$ Hence, the inference that BMI $<25$ is facilitative for vaginal delivery assumes authenticity. The present study showed that multiparity has more chances of vaginal delivery and the value was clinically significant as with other studies. ${ }^{20-23}$

Conception occurring after taking infertility treatment showed a significant effect on the mode of delivery and added significantly to the score. It could mainly be because most of such women are primigravidas and there will be low threshold for consideration to caesarean option.

Study involving a large cohort of 245, 854 singleton pregnancies from different ethnicities has shown that primary cesarean rate is directly proportional to the socioeconomic status of the women, being higher with higher income groups independent of maternal age, parity or birth weight. $^{24}$ No significant association with socioeconomic status was seen in the present study of 600 pregnancies from south India on west coast. But, the use of acquisition of BPL card as indicator of socioeconomic status can be contested.
The decision in favour of cesarean delivery in cases with severe preeclampsia is not because of obstetric reasons. ${ }^{25}$ Presence or absence of the disease did not appear to influence mode of delivery in the present study.

Increased birth weight is an independent risk factor for cesarean delivery and sonographically estimated fetal weight is not thought be a good predictor for cesarean delivery. ${ }^{19,20,22,23,26}$ Observations from the study (Table 2) are in concurrence with those reports.

Studies have shown that the AFI is not a good predictor for the increased risk of cesarean delivery. ${ }^{20,26,27}$ In the present analysis, AFI of $<5$ was associated with 1.5 times of increased risk for cesarean delivery than those with normal and high AFI pregnancies. The sample size studied and inter-observer variations because of different sonologists may have contributed to the contradicting finding.

Lower Bishop score and use of prostaglandins in labor were considered to be associated with higher caesarean deliveries, and finding from present study was no different. $^{19,22,28}$

\section{Scoring systems to decide mode of delivery}

There are studies aplenty that developed different scoring systems mainly to find out the chances of success for trial of labour in women with previous caesarean..$^{3-9,29}$ Some evaluated with a separate validation data set taken from the retrospective and prospective cohort studies ${ }^{5,7,9}$ and others evaluated the screening performance tool by examining the area under the Receiver Operating Characteristic curve obtained by plotting the true positivity rate (sensitivity) against the false positivity rate (1- specificity). ${ }^{1,6,30}$

Although these systems can be used even in pregnancies without prior caesarean deliveries since high negative predictive values imply that the scores will be useful to find out which women were unlikely to undergo caesarean delivery, the presented scoring system by encompassing all possible factors obstetric and nonobstetric seems to be more comprehensive.

The complex and repeated statistical evaluation utilized in evolving the score and the cut-off to predict mode of delivery remain strong points of the present study. The score which was developed was revalidated in two different settings with significant number of cases retrospectively on 600 women and prospectively on 235 women makes it worthy for application.

However, the re-evaluation in the same clinical facility setting is the limitation of the study. It would have been better had the developed score was tested against different hospital settings to replicate its validity. 
The score developed using non-obstetric and obstetric variables will act as a tool that will help the attending obstetrician to inform with confidence the possible chances of vaginal delivery to the parturient and her attendants. Once the anxiety about possibility of cesarean delivery is dispelled to some extent, it may further contribute to increased prospect of vaginal delivery in them. It will also be of great utility to physician at first referral units to make an informed decision about the timely transfer of laboring women who are less likely to have vaginal delivery if facilities are limited for operative obstetrics.

\section{CONCLUSIONS}

The composite score of $\leq 21$ suggests that woman will most probably have vaginal delivery and that a higher score does not always mean a caesarean delivery.

\section{ACKNOLEDGEMENT}

Authors are thankful to Medical Superintendent and Heads of the clinical Units at District Lady Goschen Hospital, Mangaluru for permitting to study the cases.

\section{Funding: No funding sources}

Conflict of interest: None declared

Ethical approval: The study was approved by the Institutional Ethics Committee

\section{REFERENCES}

1. Macones GA, Hausman N, Edelstein R, Stamilo DM, Marder SJ. Predicting outcomes of trials of laborin women attempting vaginal birth after cesarean delivery: a comparison of multivariate methods with neural networks. ACOG. 2001;184:409-13.

2. Prasad M, Al -Taher H. Maternal height and labour outcome. ObstetGynecol. 2002;22(5):513-5.

3. Troyer LR, Parisi VM. Obstetric parameters affecting success in a trial of labor: designation of a scoring system. AJOG. 1992;167: 1099-104.

4. Hashima JN, Guise JM. Vaginal birth after cesarean: a prenatal scoring tool. AJOG. 2007;1965: e22-3.

5. Flamm BL, Geiger AM. Vaginal birth after cesarean delivery- an admission scoring system. ObstetGynecol. 1997;90:907-10.

6. Grobman WA, Lai Y, Landon MB, Spong Y, Leveno KJ, Rouse DJ, et al. National Institute of Child Health and Human Development (NICHD) Maternal-Fetal Medicine Units Network (MFMU). Development of a nomogram for prediction of vaginal birth after cesarean delivery. Obstet Gynecol. 2007;109:806-12.

7. Constantine MM, Fox K, Byres BD, Mathews J, Ghulmiyyah LM, Blackwell S, et al. Validation of the prediction model for the success of vaginal birth after cesarean delivery. Obstet Gynecol. 2009;114:1029-33.
8. Gonen R, Tamir A, Degani S, Ohel G. Variables associated with successful vaginal birth after one cesarean section: a proposed vaginal birth after cesarean section score. A J Perinatol. 2004;21:44753.

9. Dinsmoor MJ, Brock EL. Predicting failed trial of labor after primary cesarean delivery. Obstet Gynecol. 2004;103:282-6.

10. Hashim N, Naqvi S, Khannam M, Jafry HF. Primigravida as an intrapartum obstetric risk factor. J Pak Med Assoc. 2012;62:694-8.

11. Dadhwal V, Mittal S, Kumar S, Anand lakshmi PN, Vimal N. Vaginal birth after cesarean deliveryvariables affecting outcome. JK Science. 2003;5:114

12. Srinivas SK, Stamilio DM, Stevens EJ, Odibo AO, Peipert JF, Macones GA. Predicting failure of a vaginal birth attempt after cesarean delivery. Obstet Gynecol. 2007;109:800-5.

13. vanKatwiik $C$, Peeters LL. Clinical aspects of pregnancy after the age of 35 years: a review of the literature. Hum Reprod Update. 1998;4:185-94.

14. Dabelea D, Snell-Bergeon JK, Hartsfield CL, Bischoff KJ, Hamman RF, McDuffie RS. Increasing prevalence of gestational diabetes mellitus (GDM) over time and by birth cohort: Kaiser Permanente of Colorado GDM Screening Program. Diabetes Care. 2005;28:579-84.

15. Sheiner E, Levy A, Katz M, Mazor M. Short stature-an independent risk factor for Cesarean delivery. Eur J Obstet Gynecol Reprod Biol. 2005;120:175-8.

16. National Institute of Health Care and Excellence: Caesarean Section. Predicting CS for cephalopelvic disproportion in labour NICE Guidelines, accessed on August 9, 2015.

17. Kominiarek MA, Vanveldhuisen P, Hibbard J, Landy $\mathrm{H}$, Haberman S, Learman L, et al. Consortium on Safe Labor. The maternal body mass index: a strong association with delivery route. Am J Obstet Gynecol. 2010;203:264.e1-7.

18. Tan PC, Suguna S, Vallikkannu N, Hassan J. Ultrasound and clinical predictors for Caesarean delivery after labour induction at term. Aust $\mathrm{N} \mathrm{Z} \mathrm{J.}$ Obstet Gynaecol. 2006;46:505-9.

19. Vrouenraets FP, Roumen FJ, Dehing CJ, van den Akker ES, Aarts MJ, Scheve EJ. Bishop score and risk of cesarean delivery after induction of labor in nulliparous women. Obstet Gynecol. 2005;105:6907.

20. Peregrine E, O'Brien P, Omar R, Jauniaux E. Clinical and ultrasound parameters to predict the risk of cesarean delivery after induction of labor. Obstet Gynecol. 2006;107(2 Pt 1):227-33.

21. Wang Y, Tanbo T, Abyholm T, Henriksen T. The impact of advanced maternal age and parity on obstetric and perinatal outcomes in singleton gestations. Arch Gynecol Obstet. 2011;284:31-7.

22. Bodner-Adler B, Bodner K, Pateisky N, Kimberger O, Chalubinski K, Mayerhofer K, Husslein P. Influence of labor induction on obstetric outcomes in 
patients with prolonged pregnancy: a comparison between elective labor induction and spontaneous onset of labor beyond term. Wien KlinWochenschr. 2005; 117:287-92.

23. Usha Kiran TS, Hemmadi S, Bethel J, Evans J. Outcome of pregnancy in a woman with an increased body mass index. BJOG. 2005; 112:768-72.

24. Gould JB, Davey B, Stafford RS. Socioeconomic differences in rates of cesarean section. $\mathrm{N}$ Engl $\mathrm{J}$ Med. 1989;321:233-9.

25. Coppage KH, Polzin WJ. Severe preeclampsia and delivery outcomes: is immediate cesarean delivery beneficial? Am J Obstet Gynecol. 2002;186:921-3.

26. Kim SN, Park KH, Jung HJ, Hong JS, Shin DM, Kang WS. Clinical and sonographic parameters at 37 weeks' gestation for predicting the risk of primary Cesarean delivery in nulliparous women. Ultrasound Obstet Gynecol. 2010;36:486-92.
27. Chen G, Uryasev S, Young TK. On prediction of the cesarean delivery risk in a large private practice. Am J Obstet Gynecol. 2004;191:616-24.

28. van der Merve AM, Thomson JMD, Ekeroma AJ. Factors affecting vaginal birth after caesarean section at Middlemore Hospital, Auckland, New Zealand. NZMJ. 2013;126:1-9.

29. Ehrenthal DB, Jiang X, Strobino DM. Labor induction and the risk of a cesarean delivery among nulliparouswomen at term. Obstet Gynecol. 2010;116:35-42.

30. Weinstein D, Benshushan A, Tanos V, Zilberstein R, Rojansky N. Predictive score for vaginal birth after cesarean section. Am J Obstet Gynecol. 1996;174(1 Pt 1):192-8.

Cite this article as: Kotha $\mathrm{S}$, Kushtagi $\mathrm{P}$,

Radhakrishnan K. Prediction of mode of delivery in term pregnancies: development of scoring system. Int J Reprod Contracept Obstet Gynecol 2015;4:128390. 